\title{
Análise multivariada dos componentes da resistência à ferrugem-asiática em genótipos de soja
}

\author{
Lucimara Junko Koga ${ }^{(1)}$, Marcelo Giovanetti Canteri(1), Éberson Sanches Calvo(2), Jair Rogério Unfried ${ }^{(2)}$, \\ Alexandre Garcia( ${ }^{(2)}$, Arlindo Harada ${ }^{(2)}$ e Romeu Afonso de Souza Kiihl(2)
}

(1)Universidade Estadual de Londrina, Departamento de Agronomia, CEP 86051-970 Londrina, PR. E-mail: lucimarakoga@tmg.agr.br, canteri@uel.br (2)Tropical Melhoramento \& Genética Ltda., Caixa Postal 387, CEP 86183-600 Cambé, PR. E-mail: ebersoncalvo@tmg.agr.br, jairunfried@tmg.agr.br, alexandregarcia@uol.com.br, arlindoharada@tmg.com.br, romeukiihl@tmg.agr.br

Resumo - O objetivo deste trabalho foi detalhar os ciclos de infecção da Phakopsora pachyrhizi Syd. \& P. Syd. em genótipos de soja, para o estabelecimento de grupos de genótipos mais promissores para o uso como fontes de resistência à ferrugem. Os componentes do ciclo de infecção foram quantificados em 48 genótipos. Foram avaliados: tipo de lesão, intensidade de esporulação, severidade, número de lesões e de urédias e produtividade de urediniósporos. Pela análise de agrupamentos, formaram-se quatro grupos: A - desenvolveu a maior quantidade de doença; $\mathrm{B}$ - desenvolveu a menor quantidade de doença; $\mathrm{C}$ - baixa resistência inicial e D - alta resistência inicial. Os genótipos dos grupos B, C e D apresentaram lesões RB ("redish-brown") e variaram quanto à resistência inicial, resistência tardia, intensidade de esporulação, estabilidade da resposta qualitativa, produtividade de urediniósporos e número de dias para atingir $50 \%$ da severidade máxima. Entre as variáveis analisadas, as que apresentaram importância prática foram as avaliações das respostas qualitativas e as de severidade. Esta última reflete os efeitos combinados de resistência sobre todos os componentes da infecção e apresentam importância prática na diferenciação de genótipos, quanto à resistência à doença. Os genótipos dos grupos $\mathrm{B}, \mathrm{C}$ e D manifestaram resistência qualitativa e quantitativa, em diferentes graus, e promissores para serem utilizados como fontes de genes de resistência à ferrugem-asiática-da-soja.

Termos para indexação: Glycine max, Phakopsora pachyrhizi, epidemiologia, número de lesões, número de urédias, resistência horizontal e vertical, resistência quantitativa e qualitativa.

\section{Multivariate analysis of resistance components to Asian rust in soybean genotypes}

\begin{abstract}
The objective of this study was to detail the infection cycles of Phakopsora pachyrhizi Syd. \& P. Syd. in soybean genotypes, in order to establish a group of the most promising genotypes for use as sources of resistance to Asian soybean rust. The infection cycle components were quantified in 48 genotypes. The assessments consisted of: type of lesion, intensity of sporulation, severity, number of lesions and uredinias, and productivity of urediniospores. The cluster analysis formed four groups: A - developed the highest amount of disease; $\mathrm{B}$ - developed the lowest amount of disease; $\mathrm{C}$ - low initial resistance; and D - high initial resistance. All the genotypes of groups B, C and D had RB (redish-brown) lesions and varied for initial resistance, delayed resistance, intensity of sporulation, stability of the qualitative response, productivity of urediniospores, and number of days to reach $50 \%$ of the maximum severity. Qualitative responses and disease severity evaluations reflect the combined effects of resistance on all the infection components and show practical importance in genotypes differentiation, regarding disease resistance. The genotypes of groups B, C and D presented qualitative and quantitative resistance, in different degrees, and they are promising genotypes as sources of resistance to Asian soybean rust.
\end{abstract}

Index terms: Glycine max, Phakopsora pachyrhizi, epidemiology, number of lesions, number of uredinias, horizontal and vertical resistance, quantitative and qualitative resistance.

\section{Introdução}

A ferrugem-asiática-da-soja, causada pelo fungo Phakopsora pachyrhizi Syd. \& P. Syd., é considerada altamente agressiva e foi reportada pela primeira vez na América do Sul em 2001, detectada primeiramente no Paraguai e, logo em seguida, no Brasil (Yorinori \& Lazzarotto, 2004). As plantas de soja são suscetíveis ao fungo em todos os estádios de crescimento, e as perdas 
podem ser de até 100\% (Hartman et al., 1991; Kawuki et al., 2003; Yorinori, 2006).

As pesquisas têm-se concentrado na obtenção de cultivares resistentes. Cinco genes dominantes, denominados Rppl (McLean \& Byth, 1980), Rpp2 (Bromfield \& Hartwig, 1980), Rpp3 (Hartwig \& Bromfield, 1983), Rpp4 (Hartwig, 1986) e Rpp5 (Garcia et al., 2008), que condicionam a resistência vertical (qualitativa), já foram relatados na literatura, mas a estabilidade desse tipo de resistência pode não ser durável, quando testada em campo (Hartman et al., 2005). Portanto, a identificação de genótipos que possam ser utilizados como fontes para a resistência horizontal (quantitativa) certamente ajudará a aumentar a longevidade das cultivares lançadas no mercado.

Alguns autores mencionam a necessidade de busca de genótipos que possuam resistência horizontal ou taxa reduzida de progresso da doença (Bergamin Filho \& Amorim, 1996; Hartman et al., 1997, 2005), em razão da alta capacidade de adaptação e presença de fatores múltiplos de virulência da $P$. pachyrhizi (Burdon \& Speer, 1984; Tschanz \& Wang, 1985; Yamaoka et al., 2002).

Para a identificação de germoplasma com resistência quantitativa, é necessário o detalhamento dos ciclos primários (monociclos) e secundários (policiclos) da doença. Os processos monocíclicos se completam em um único ciclo de infecção. São constituídos pelos períodos de incubação (deposição dos esporos até o aparecimento dos sintomas), de latência (deposição dos esporos até o aparecimento dos sinais) e pelo período infeccioso (da esporulação até a morte da lesão) (Bergamin Filho et al., 1995). Também é necessário o detalhamento do ciclo secundário que, no caso da ferrugem-da-soja, é a produção de novas urédias. Essa variável é pouco dependente das condições climáticas e supre a epidemia constantemente com novos urediniósporos (Bergamin Filho, 2006).

Entre os possíveis mecanismos responsáveis pela diminuição do progresso de doenças, ao longo do tempo, destacam-se: a baixa freqüência de infecção, a diminuição do desenvolvimento do micélio dentro do tecido do hospedeiro, o período latente longo, e a baixa produção de esporos (Heagle \& Moore, 1970; Parlevliet, 1979).

O presente trabalho teve como objetivo detalhar os ciclos de infecção de P. pachyrhizi, em genótipos de soja pré-selecionados, para o estabelecimento de grupos de genótipos mais promissores a serem utilizados como fontes de genes de resistência à ferrugem-asiática-dasoja em programas de melhoramento genético.

\section{Material e Métodos}

Foram utilizadas três cultivares como testemunhas suscetíveis à ferrugem (BRS 154, BRSMS Bacuri e CD 208) e 45 genótipos disponíveis no banco de germoplasma da empresa Tropical Melhoramento \& Genética Ltda., que apresentaram, em avaliações preliminares, respostas de hipersensibilidade, caracterizada pela formação de lesões do tipo RB ("redish-brown") de resistência. As sementes foram semeadas em casa de vegetação no dia 6/6/2007, em vasos de plástico com $3 \mathrm{~kg}$ de mistura de terra, areia e esterco (5:1:1), mais $0-20-20$ de NPK (8 g por vaso). O delineamento experimental foi o de blocos ao acaso, com três repetições, e a parcela experimental foi constituída por três vasos, com uma planta em cada. As plantas de cada repetição receberam numeração: planta 1,2 e 3 .

O inóculoutilizado foio dapopulaçãode P.pachyrhizi, presente na região de Cambé, PR. Os urediniósporos da ferrugem foram multiplicados em plantas da cultivar BRSMS Bacuri. Foi realizada a quantificação em hemacitômetro, e se produziu uma suspensão com concentração de $5 \times 10^{4}$ urediniósporos $\mathrm{mL}^{-1}$.

A inoculação foi realizada aos 29 dias após a semeadura, quando as plantas encontravam-se nos estádios V4 ou V5 (Fehr \& Caviness, 1977), conforme o genótipo. Os trifólios que receberam a inoculação foram marcados com um barbante. As plantas foram mantidas em casa de vegetação, com emprego de nebulizações apenas após a inoculação, para garantir 12 horas de molhamento foliar. As médias das temperaturas máxima e mínima registradas no período foram 30 e $14^{\circ} \mathrm{C}$, respectivamente.

As avaliações do período de incubação (dias decorridos entre a data de inoculação até o aparecimento dos primeiros sintomas ou lesões) e da severidade (SEV) foram realizadas nas plantas 1 . Os valores de severidade foram estimados semanalmente, de acordo com Godoy et al. (2006), para cada um dos 48 genótipos estudados, a partir dos primeiros sintomas até a estabilização do progresso da doença, no trifólio marcado.

Em seguida, foi realizada a contagem dos dias entre a inoculação e o dia em que a nota de severidade atingiu 
$50 \%$ da nota final (SEV50\%). Dessa forma, foi obtido o intervalo de tempo (em dias) transcorrido entre o início da infecção até a SEV50\%. Nas avaliações em laboratório, realizadas aos 15 dias após inoculação (DAI) e aos 29 DAI, também foi avaliada a severidade da doença (SEV15 e SEV29) nos trifólios coletados das plantas 2 e 3, respectivamente.

Para a taxa de infecção aparente, que representa novas lesões por dia (Bergamin Filho et al., 1995), os modelos exponencial, logístico, Gompertz e monomolecular foram ajustados aos dados de progresso da severidade. $\mathrm{O}$ ajuste foi realizado pela análise dos coeficientes de determinação da regressão, entre os valores observados e os previstos, não transformados. O melhor ajuste foi obtido com o modelo monomolecular, que apresentou o maior coeficiente de determinação para $68,75 \%$ dos genótipos avaliados.

Com os valores de severidade, foi possível calcular a taxa de infecção aparente (TxTr), pela equação do modelo monomolecular (Bergamin Filho et al., 1995), e a área abaixo da curva de progresso da doença (AATr) (Campbell \& Madden, 1990).

Os trifólios marcados das plantas 2 e 3 também foram utilizados para as avaliações do tipo de lesão aos 15 DAI (TLS15) e aos 29 DAI (TLS29). A classificação do tipo de lesão foi realizada de acordo com a metodologia descrita por Bromfield (1984): TAN ("tanish"), de coloração palha, com pouca necrose; RB ("redishbrown"), de coloração marrom-avermelhada escura, com necrose extensa; e MX ("mixed"), quando se observou a presença dos dois tipos de lesão na mesma folha.

Nos mesmos trifólios foram avaliados a intensidade de esporulação (ESP15 e ESP29), por meio de uma escala de notas (Figura 1), o número de lesões (NLS15 e NLS29), o número de urédias (NUD15 e NUD29) e a produtividade de urediniósporos (PRE15 e PRE29).

Para a quantificação do número de lesões, número de urédias e produtividade de urediniósporos contou-se com o auxílio de um vazador de $1 \mathrm{~cm}$ de diâmetro. Foram cortados três discos da área mais afetada dos folíolos de cada genótipo. Os três discos foram colocados em tubos com $1 \mathrm{~mL}$ de solução de água destilada, com $0,1 \%$ Tween $20(\mathrm{v} / \mathrm{v})$. Em seguida, os tubos foram agitados por $30 \mathrm{~min}$, a $150 \mathrm{rpm}$, a $23 \pm 2^{\circ} \mathrm{C}$, em mesa agitadora Gallenkamp, para que os urediniósporos fossem liberados na solução. Após esta etapa, os discos foram retirados dos tubos e acondicionados em placas de Petri.
A contagem do número de lesões (NLS) e de urédias (NUD), nos discos, foi realizada em microscópio de computador Digital Blue QX5, com aumentos de 10x e 60x, respectivamente. A partir desses dados, foi estimada a relação do número de urédias por lesão (ULS15 e ULS29), em ambas as avaliações.

A quantificação da produtividade de urediniósporos foi realizada com o auxílio do hemacitômetro. Foi retirada uma alíquota das soluções contendo os urediniósporos de cada genótipo. Esses valores, juntamente com os dados de NUD15 e NUD29, foram usados para calcular o número de urediniósporos por urédia (EUR15 e EUR29).

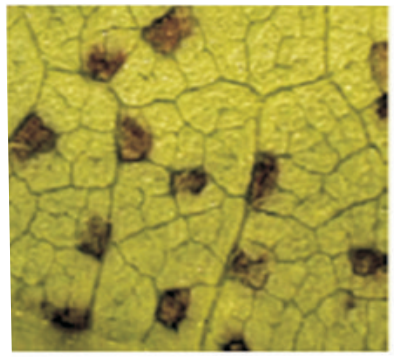

RB1

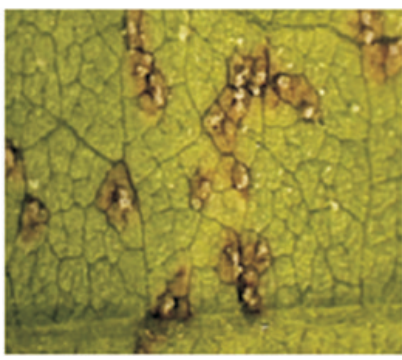

RB3

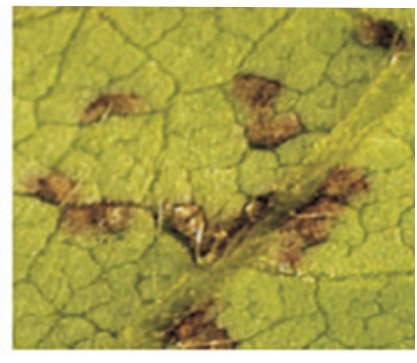

RB2

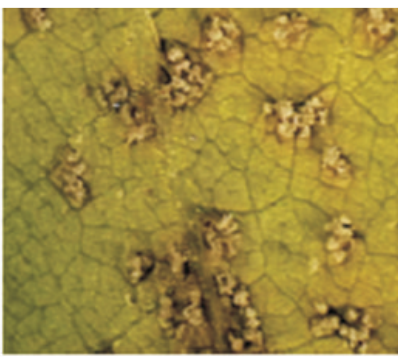

RB4

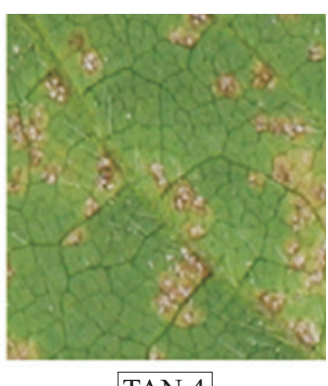

TAN 4

Figura 1. Intensidade da esporulação de Phakopsora pachyrhizi em folhas de soja (adaptado de Miles, 2006). RB1: sem presença de urediniósporos; RB2: presença esparsa de urediniósporos, algumas lesões sem urediniósporos; RB3: presença moderada de urediniósporos em todas as lesões; RB4/TAN4: presença abundante de urediniósporos em todas as lesões. 
Tendo-se em vista a necessidade de caracterizar os genótipos de acordo com um conjunto de variáveis, analisadas simultaneamente, dois métodos estatísticos de análise multivariada foram usados: análise fatorial, pelo método de componentes principais, e análise de agrupamento, pelo método de K-médias. Para decidir sobre o número de fatores extraídos a serem utilizados para a análise fatorial, utilizou-se o critério da raiz latente (Harman, 1976), que considera que qualquer fator individual deve explicar a variância de pelo menos uma variável. Apenas os fatores que têm raízes latentes ou autovalores maiores que 1 são considerados significativos. Contudo, neste trabalho, o fator 4 foi incluído. Isso porque seu autovalor foi próximo de 1 $(0,89)$ e ele explicou a variância da variável EUR29.

O conhecimento prévio das variáveis-chave é importante, pois elas refletem os fatores latentes, que foram gerados hipoteticamente. As cargas indicam o grau de correspondência entre a variável e o fator, e as variáveis com as maiores cargas são as mais representativas. As denominações dos fatores foram estabelecidas de acordo com o conjunto de variáveischave ou pela variável que mais fortemente representou $o$ fator.

A partir dos quatro fatores obtidos na análise fatorial, foi realizada a análise de agrupamentos. O procedimento foi usado para maximizar a homogeneidade de objetos dentro de grupos, ao mesmo tempo em que maximizou a heterogeneidade entre os grupos. $O$ número de grupos foi definido a partir de uma fundamentação prática, estabelecida em razão de os genótipos padrão de suscetibilidade à ferrugem-asiática (BRS 154, BRSMS Bacuri e CD 208) situarem-se no mesmo grupo, o que não ocorreu quando foram gerados cinco grupos ou mais. As denominações foram conferidas com base nas características mais relevantes de cada grupo (Hair Junior et al., 2005).

Para o processamento dos dados, usou-se o programa Statistical Program for Social Sciences (SPSS), versão 7.5 para Windows. Após a formação dos grupos, os dados foram submetidos à análise de variância, e as médias foram comparadas pelo teste de Tukey, a 1\% de probabilidade, com uso do programa SASM-Agri (Canteri et al., 2001).

\section{Resultados e Discussão}

Os quatro fatores usados na análise fatorial, pelo método de componentes principais, explicaram $84,82 \%$ da variância observada nas 15 variáveis (SEV50\%, AATr, SEV15, SEV29, NLS15, NLS29, NUD15, NUD29, PRE15, PRE29, ULS15, ULS29, TxTr, EUR15, EUR29).

Todos os parâmetros apresentaram valores altos (maiores que 0,70$)$ e significativos quanto à comunalidade (Tabela 1) e, portanto, nenhum foi descartado.

Segundo Hair Junior et al. (2005), quando o tamanho de uma amostra é menor que 100 , como no presente trabalho (foram utilizados 48 genótipos), a menor carga fatorial a ser considerada significativa é $\pm 0,30$. Portanto, todas as variáveis encaixaram-se na exigência mínima de significância prática (Tabela 1).

Os dados de período de incubação variaram de 3 a 6 dias e não foram usados nas análises multivariadas. Esse parâmetro não foi importante para diferenciar os genótipos, pois alguns deles apresentaram aparecimento abundante de lesões em algumas datas, enquanto outros, nessas mesmas datas, apresentaram apenas uma ou duas lesões. Essa variação se deveu ao fato de terem sido avaliados genótipos com respostas de suscetibilidade (lesões TAN) e resistência (lesões RB). Além disso, dentro dos genótipos com lesões RB, ocorreram expressões

Tabela 1. Matriz das cargas fatoriais, comunalidades das variáveis, autovalores e variância explicada total e por fator.

\begin{tabular}{|c|c|c|c|c|c|}
\hline \multirow[t]{2}{*}{ Variável $^{(1)}$} & \multicolumn{4}{|c|}{ Cargas fatoriais para os fatores } & \multirow[t]{2}{*}{ Comunalidades } \\
\hline & 1 & 2 & 3 & 4 & \\
\hline$\overline{\mathrm{SEV} 50 \%}$ & $-0,68$ & 0,37 & 0,29 & 0,23 & 0,73 \\
\hline $\mathrm{AATr}$ & 0,89 & $-0,24$ & $-0,06$ & $-0,02$ & 0,85 \\
\hline SEV15 & 0,87 & $-0,29$ & $-0,26$ & $-0,04$ & 0,91 \\
\hline SEV29 & 0,86 & $-0,21$ & 0,15 & 0,16 & 0,83 \\
\hline NLS15 & 0,90 & $-0,24$ & $-0,20$ & $-0,02$ & 0,91 \\
\hline NLS29 & 0,89 & $-0,24$ & 0,06 & 0,21 & 0,90 \\
\hline NUD15 & 0,90 & 0,31 & $-0,10$ & 0,07 & 0,92 \\
\hline NUD29 & 0,91 & 0,18 & 0,25 & 0,04 & 0,93 \\
\hline PRE15 & 0,92 & 0,17 & 0,01 & 0,08 & 0,88 \\
\hline PRE29 & 0,87 & 0,20 & 0,20 & 0,04 & 0,83 \\
\hline ULS15 & 0,57 & 0,67 & $-0,14$ & 0,02 & 0,79 \\
\hline ULS29 & 0,29 & 0,72 & 0,24 & $-0,52$ & 0,92 \\
\hline $\operatorname{Tx} \operatorname{Tr}$ & 0,57 & $-0,04$ & 0,58 & 0,25 & 0,73 \\
\hline EUR15 & $-0,39$ & $-0,49$ & 0,56 & $-0,15$ & 0,72 \\
\hline EUR29 & $-0,57$ & 0,36 & $-0,10$ & 0,63 & 0,86 \\
\hline Autovalores & 8,80 & 1,95 & 1,08 & 0,89 & 12,72 \\
\hline Variância explicada (\%) & 58,66 & 13,03 & 7,18 & 5,95 & 84,82 \\
\hline
\end{tabular}

${ }^{(1)}$ SEV50\%: dias entre a inoculação e o dia em que a nota de severidade atingiu $50 \%$ da nota final; AATr: área abaixo da curva de progresso da doença; SEV15 e SEV29: severidade aos 15 e aos 29 dias da inoculação; NLS15 e NLS29: número de lesões aos 15 e aos 29 dias da inoculação; NUD15 e NUD29: número de urédias aos 15 e aos 29 dias da inoculação; PRE15 e PRE29: produtividade de urediniósporos aos 15 e aos 29 dias da inoculação; ULS15 e ULS29: número de urédias por lesão aos 15 e aos 29 dias da inoculação; TxTr: taxa de infecção aparente; EUR15 e EUR29: número de urediniósporos por urédia aos 15 e aos 29 dias da inoculação. ${ }^{(2)} \mathrm{A}$ comunalidade assume valores de 0 a 1 , em que: $>0,70$ é considerada alta; 0,50 a 0,69, média; e <0,49, baixa. 
da doença em diferentes graus. Em decorrência disso, a inclusão dessa variável na análise fatorial prejudicou o ajuste geral do modelo, por conferir o mesmo período de incubação a genótipos com respostas totalmente distintas.

O fator 1 foi denominado de quantidade de doença, por ter apresentado, entre os quatro fatores, o maior número de variáveis relacionadas à quantificação da doença. Foi o principal componente da análise fatorial, pois explicou $58,66 \%$ da variância (Tabela 1). As variáveis AATr, SEV15, SEV29, NLS15, NLS29, NUD15, NUD29, PRE15 e PRE29 correlacionaram-se positivamente a esse fator, e apresentaram cargas fatoriais altas, que variaram de 0,86 a 0,92 .

$\mathrm{O}$ fator 2 (Tabela 1) foi denominado número de urédias por lesão, pois correlacionou-se a ULS15 e ULS29 - que variaram juntas, o que indicou que ambas aumentaram na mesma direção -, e explicou $13,03 \%$ da variância.

As variáveis TxTr e EUR15 correlacionaram-se positivamente ao fator 3 , que foi denominado taxa de infecção aparente, e explicou $7,18 \%$ da variância. O fator 4, denominado número de esporos por urédia na segunda avaliação (EUR29), foi significativo apenas nessa variável (disso decorreu sua denominação) e explicou 5,95\% da variância total.

Na Tabela 2, estão representados os quatro grupos de genótipos formados - resultado principal da análise de agrupamentos -, que se deu a partir dos valores obtidos na análise fatorial. Os valores apresentados na Tabela 3 apóiam as descrições dos grupos de genótipos formados pela análise de agrupamentos. $\mathrm{O}$ valor de um determinado fator mostra a posição relativa do grupo de genótipos quanto às características dominantes do fator.

O grupo A, que agregou os genótipos que desenvolveram a maior quantidade de doença, foi constituído por seis genótipos, entre os quais os três padrões de suscetibilidade, que apresentaram as lesões TAN, nas avaliações 15 e 29 DAI, com alta esporulação (TAN4) (Tabela 2). Os três demais genótipos desse grupo apresentaram lesões RB, contudo, também foram avaliados como tendo alta esporulação (RB4).

Com base nos resultados da Tabela 3, foi constatado que o grupo A carregou positivamente (valores maiores que 0,50 ) nos fatores 1,2 e 3 , o que significa que os genótipos desse grupo apresentaram maior quantidade de doença total (AATr), maior porcentagem de área doente (SEV15 e SEV29), maior número de lesões (NLS15 e NLS29), maior número de urédias (NUD15 e NUD29), maior produtividade de urediniósporos (PRE15 e PRE29), e menos dias decorridos até o trifólio marcado atingir $50 \%$ de severidade máxima (SEV50\%).

Tabela 2. Análise de agrupamentos de genótipos de soja, tipo de lesão (TLS) e nota de intensidade de esporulação (ESP), de acordo com a escala de notas descrita na Figura 1, aos 15 e 29 dias da inoculação ${ }^{(1)}$.

\begin{tabular}{|c|c|c|c|c|c|}
\hline Genótipo & Grupos & TLS15 & TLS29 & ESP15 & ESP29 \\
\hline BRS 154 & A & TAN & TAN & TAN4 & TAN4 \\
\hline Bacuri & A & TAN & TAN & TAN4 & TAN4 \\
\hline CD 208-1 & A & TAN & TAN & TAN4 & TAN4 \\
\hline PI $230970 \mathrm{SH}$ & A & $\mathrm{RB}$ & $\mathrm{RB}$ & TAN4 & TAN4 \\
\hline PI 224270-1 & A & $\mathrm{RB}$ & $\mathrm{RB}$ & RB4 & RB4 \\
\hline ER04-6887-1 & A & $\mathrm{RB}$ & RB & RB3 & RB4 \\
\hline ER04-6881 & B & $\mathrm{RB}$ & MX & RB2 & RB2 e TAN4 \\
\hline ER04-6883 & B & $\mathrm{RB}$ & MX & RB1 & RB1 e TAN4 \\
\hline ER04-6884-1 & B & $\mathrm{RB}$ & $\mathrm{RB}$ & RB1 & RB1 \\
\hline ER04-6886 & B & $\mathrm{RB}$ & $\mathrm{RB}$ & RB1 & RB1 \\
\hline ER04-6892-2 & B & $\mathrm{RB}$ & MX & RB1 & RB1 e TAN4 \\
\hline ER06-2164 & $\mathrm{C}$ & $\mathrm{RB}$ & $\mathrm{RB}$ & RB3 & RB3 \\
\hline GC 00138-29-0 & $\mathrm{C}$ & $\mathrm{RB}$ & $\mathrm{RB}$ & RB3 & RB3 \\
\hline GC 00138-29-1 & $\mathrm{C}$ & $\mathrm{RB}$ & $\mathrm{RB}$ & RB3 & RB3 \\
\hline GC 00138-29-3 & $\mathrm{C}$ & $\mathrm{RB}$ & RB & RB3 & RB3 \\
\hline GC 00138-29-4 & $\mathrm{C}$ & $\mathrm{RB}$ & $\mathrm{RB}$ & RB3 & RB3 \\
\hline GC 84058-21-4-1 & $\mathrm{C}$ & $\mathrm{RB}$ & $\mathrm{RB}$ & RB3 & RB4 \\
\hline GC 84058-21-4-4 & $\mathrm{C}$ & $\mathrm{RB}$ & $\mathrm{RB}$ & RB3 & RB4 \\
\hline PI 230971 & $\mathrm{C}$ & $\mathrm{RB}$ & MX & RB3 & RB4 e TAN4 \\
\hline PI 459025 A-1 & $\mathrm{C}$ & $\mathrm{RB}$ & $\mathrm{RB}$ & RB4 & RB4 \\
\hline PI 459025 B-2 & C & $\mathrm{RB}$ & $\mathrm{RB}$ & RB3 & RB4 \\
\hline G 10428-1 & $\mathrm{C}$ & $\mathrm{RB}$ & $\mathrm{RB}$ & RB3 & RB4 \\
\hline Shiranui-1-2 & $\mathrm{C}$ & $\mathrm{RB}$ & MX & RB3 & RB3 e TAN4 \\
\hline PI 471904-1 & $\mathrm{C}$ & $\mathrm{RB}$ & $\mathrm{RB}$ & RB3 & RB3 \\
\hline PI 471904-2 & $\mathrm{C}$ & $\mathrm{RB}$ & MX & RB3 & RB3 e TAN4 \\
\hline PI 471904-3 & $\mathrm{C}$ & $\mathrm{RB}$ & MX & RB3 & RB4 e TAN4 \\
\hline PI 200487 & $\mathrm{C}$ & $\mathrm{RB}$ & $\mathrm{RB}$ & RB3 & RB3 \\
\hline PI 200456 & $\mathrm{C}$ & $\mathrm{RB}$ & $\mathrm{RB}$ & RB4 & RB4 \\
\hline PI 197182 & $\mathrm{C}$ & $\mathrm{RB}$ & MX & RB3 & RB3 e TAN4 \\
\hline PI 197182-1 & $\mathrm{C}$ & $\mathrm{RB}$ & $\mathrm{RB}$ & RB2 & $\mathrm{RB} 2$ \\
\hline PI 200455 & $\mathrm{C}$ & $\mathrm{RB}$ & MX & RB3 & RB4 e TAN4 \\
\hline PI $379618-2$ & $\mathrm{C}$ & $\mathrm{RB}$ & $\mathrm{RB}$ & RB3 & RB3 \\
\hline PI 416764 & $\mathrm{C}$ & $\mathrm{RB}$ & MX & RB4 & RB4 e TAN4 \\
\hline PI 416810 & $\mathrm{C}$ & $\mathrm{RB}$ & MX & RB3 & RB3 e TAN4 \\
\hline PI 416819 & $\mathrm{C}$ & $\mathrm{RB}$ & $\mathrm{RB}$ & RB3 & RB3 \\
\hline PI 417125 & $\mathrm{C}$ & $\mathrm{RB}$ & $\mathrm{RB}$ & RB3 & RB4 \\
\hline ER04-6889 & $\mathrm{C}$ & $\mathrm{RB}$ & $\mathrm{RB}$ & RB3 & RB4 \\
\hline ER04-6890 & $\mathrm{C}$ & $\mathrm{RB}$ & MX & RB4 & RB4 e TAN4 \\
\hline ER04-6891 & $\mathrm{C}$ & $\mathrm{RB}$ & $\mathrm{RB}$ & $\mathrm{RB} 1$ & $\mathrm{RB} 2$ \\
\hline ER04-6896 & $\mathrm{C}$ & $\mathrm{RB}$ & $\mathrm{RB}$ & $\mathrm{RB} 1$ & RB2 \\
\hline ER06-2163 & $\mathrm{D}$ & $\mathrm{RB}$ & $\mathrm{RB}$ & RB2 & RB3 \\
\hline PI 379618-1 & $\mathrm{D}$ & $\mathrm{RB}$ & $\mathrm{RB}$ & RB3 & RB3 \\
\hline PI 417115 & $\mathrm{D}$ & $\mathrm{RB}$ & MX & RB3 & RB3 e TAN4 \\
\hline PI 423966 & $\mathrm{D}$ & $\mathrm{RB}$ & MX & RB2 & RB3 e TAN4 \\
\hline ER04-6893 & $\mathrm{D}$ & $\mathrm{RB}$ & $\mathrm{RB}$ & $\mathrm{RB} 1$ & RB2 \\
\hline ER04-6894 & $\mathrm{D}$ & $\mathrm{RB}$ & MX & RB1 & RB2 e TAN4 \\
\hline ER04-6895 & $\mathrm{D}$ & $\mathrm{RB}$ & $\mathrm{RB}$ & RB1 & RB2 \\
\hline ER04-6897 & $\mathrm{D}$ & $\mathrm{RB}$ & $\mathrm{RB}$ & RB1 & RB2 \\
\hline
\end{tabular}

(1)TAN ("tanish"): coloração palha, com pouca necrose; RB ("redishbrown"): coloração marrom-avermelhada escura, com necrose extensa; MX ("mixed"): presença dos dois tipos de lesão na mesma folha. 
O fator 2 demonstrou que esses seis genótipos apresentaram alto número de urédias por lesão (ULS15 e ULS29), possivelmente em decorrência da intensa produção de urédias, muito próximas umas as outras nas lesões existentes (Tabelas 3 e 4). O fator 3, que também apresentou alta carga fatorial no grupo A, mostrou que os genótipos desse grupo foram os que apresentaram a maior taxa de infecção aparente (TxTr), bem como os maiores valores de urediniósporos por urédia na primeira avaliação (EUR15). Todas as variáveis corroboraram a denominação atribuída a esse grupo.

O grupo $\mathrm{B}$, constituído pelos genótipos que desenvolveram a menor quantidade de doença, foi integrado por cinco genótipos. Três deles apresentaram lesões RB (esporulação RB1 e RB2) na avaliação aos 15 DAI, e lesões MX (esporulação RB1, RB2 e TAN4) na avaliação aos 29 DAI. Os outros dois genótipos mantiveram lesões RB (esporulação RB1), em ambas as avaliações (Tabela 2). Esse grupo caracterizou-se por carregar negativamente no fator 1 , o que indica a antonímia aos genótipos do grupo A. Isto é, são os genótipos que apresentaram um maior número de dias decorridos até o trifólio marcado atingir SEV50\%

Tabela 3. Valores médios dos fatores para formar os grupos de genótipos de soja ${ }^{(1)}$.

\begin{tabular}{lrrrr}
\hline Grupos & \multicolumn{4}{c}{ Fatores } \\
\cline { 2 - 5 } & \multicolumn{1}{c}{1} & 2 & \multicolumn{1}{c}{3} & \multicolumn{1}{c}{4} \\
\hline A & 1,54 & 0,87 & 1,09 & $-0,20$ \\
B & $-1,98$ & 1,61 & 0,37 & 0,35 \\
C & 0,16 & $-0,18$ & $-0,59$ & 0,10 \\
D & $-0,50$ & $-1,00$ & 1,10 & $-0,43$ \\
\hline
\end{tabular}

${ }^{(1)}$ Valores positivos $(>0,5)$ e negativos $(<-0,5)$ significam concordância e antonímia, respectivamente, em relação às características do fator. e tiveram os menores valores para as demais nove variáveis que compõem o fator 1 (Tabela 3).

Outro fator que se correlacionou ao grupo B foi o fator 2. De forma similar ao grupo $\mathrm{A}$, os cinco genótipos também apresentaram altos valores de ULS15 e ULS29. Isso provavelmente ocorreu pelo fato de o número de lesões ter sido muito baixo (média de 2,43 lesões por disco, aos 15 DAI). Assim, mesmo com o número muito baixo de urédias (média de 3,13 urédias por disco, aos $15 \mathrm{DAI}$ ), quando foi realizado o cálculo para se obterem os valores de ULS, a correlação ficou alta (média de 2,09 ULS, aos 15 DAI). A média de ULS no grupo A foi de 3,77 aos 15 DAI, e os valores dos NLS e NUD de 44,04 e 162,80, respectivamente, aos 15 DAI (Tabela 4).

$\mathrm{O}$ grupo $\mathrm{B}$, quando analisado em conjunto com os outros três grupos, apresentou SEV50\% quatro dias mais longa, aproximadamente (Tabela 4). Essa reação influenciou significativamente no atraso da epidemia, o que ficou bem caracterizado pela baixa quantidade de doença e, também, pelos baixos valores das demais variáveis.

$\mathrm{O}$ grupo $\mathrm{C}$, denominado de genótipos com baixa resistência inicial, abrangeu vinte e nove genótipos. Todos apresentaram lesões RB na primeira avaliação, e nove deles (31\%) apresentaram lesões MX na segunda avaliação. Quanto à esporulação, para 26 genótipos $(89,66 \%)$ ela foi de média a alta, em ambas as avaliações.

Observou-se que o grupo $\mathrm{C}$ carregou negativamente no fator 3 (taxa de infecção aparente do trifólio marcado) (Tabela 3). Uma possível explicação para esse fator

Tabela 4. Valores médios por grupo das variáveis de resistência quantitativa à ferrugem-asiática-da-soja.

\begin{tabular}{|c|c|c|c|c|c|}
\hline Variável & Grupo A & Grupo B & Grupo C & Grupo D & CV (\%) \\
\hline PI (dias) & 4,17 & 5,80 & 3,72 & 4,00 & - \\
\hline SEV $50 \%$ (dias) & 7,84 & 11,91 & 7,60 & 8,34 & - \\
\hline TxTr & 3,20 & 0,53 & 1,30 & 2,05 & - \\
\hline AATr & $244,28 \mathrm{a}$ & $27,19 \mathrm{c}$ & $185,44 \mathrm{~b}$ & $143,36 b$ & 14,21 \\
\hline SEV15 (\%) & $7,33 \mathrm{a}$ & $0,37 \mathrm{c}$ & $6,00 \mathrm{a}$ & $3,96 \mathrm{~b}$ & 15,48 \\
\hline NLS15 & $44,04 a$ & $2,43 \mathrm{c}$ & $33,82 \mathrm{a}$ & $21,17 \mathrm{~b}$ & 15,73 \\
\hline NUD15 & $162,80 \mathrm{a}$ & $3,13 \mathrm{~d}$ & $83,93 b$ & $21,02 \mathrm{c}$ & 13,68 \\
\hline PRE15 & $23.611,11 \mathrm{a}$ & $1.033,34 \mathrm{~d}$ & $11.812,26 \mathrm{~b}$ & $4.958,33 \mathrm{c}$ & 11,72 \\
\hline ULS15 & $3,77 \mathrm{~b}$ & $2,09 \mathrm{~b}$ & $2,51 \mathrm{~b}$ & $0,94 \mathrm{a}$ & 12,16 \\
\hline EUR15 & $148,96 a$ & $226,62 \mathrm{a}$ & $157,06 \mathrm{a}$ & $444,64 a$ & 76,74 \\
\hline SEV29 (\%) & $11,78 \mathrm{a}$ & $0,79 \mathrm{c}$ & $7,15 b$ & $6,69 b$ & 7,97 \\
\hline NLS29 & $89,14 a$ & $7,03 \mathrm{c}$ & $58,36 \mathrm{~b}$ & $51,70 \mathrm{~b}$ & 4,75 \\
\hline NUD29 & $344,79 a$ & $16,15 \mathrm{~d}$ & $151,02 \mathrm{~b}$ & $92,33 \mathrm{c}$ & 5,56 \\
\hline PRE29 & $64.222,22 \mathrm{a}$ & $8.000,00 \mathrm{~d}$ & $35.781,61 \mathrm{~b}$ & $22.208,33 \mathrm{c}$ & 1,14 \\
\hline ULS29 & $4,02 \mathrm{a}$ & $3,21 \mathrm{a}$ & $2,82 \mathrm{ab}$ & $1,88 \mathrm{~b}$ & 15,29 \\
\hline EUR29 & $188,22 \mathrm{a}$ & $981,43 \mathrm{c}$ & $261,31 \mathrm{~b}$ & $268,10 \mathrm{~b}$ & 9,73 \\
\hline
\end{tabular}

${ }^{(1)}$ Médias seguidas por letras iguais, nas linhas, não diferiram entre si pelo teste de Tukey, a 1\% de probabilidade; grupos A, B, C e D: os valores representam, respectivamente, as médias de $6,5,29$ e 8 genótipos. 
ter sido a variável que classificou esses genótipos é a capacidade do patógeno de conseguir expressar grande virulência, colonização e reprodução, logo no início do estabelecimento da relação patógeno-hospedeiro. Esta constatação pode ser confirmada pela alta esporulação, com pico de manifestação da doença logo na primeira avaliação, e valores de severidade e de TxTr similares ao grupo dos padrões de suscetibilidade (grupo A) (Tabelas 2 e 4 e Figura 2).

No entanto, ao se analisar a Figura 2, observa-se que ocorreu uma queda drástica na TxTr nesse grupo, a partir da avaliação feita aos 15 DAI, e os valores mantiveram-se inferiores aos dos grupos $\mathrm{A}$ e $\mathrm{D}$, até a última avaliação, o que evidencia um tipo de resistência manifestada tardiamente, ativada no decorrer do desenvolvimento da planta.

$\mathrm{O}$ grupo $\mathrm{D}$, que reuniu os genótipos denominados com alta resistência inicial, carregou negativamente nos fatores 1 e 2 e correlacionou-se positivamente ao fator 3 (Tabela 3). A partir dessas informações, foi possível observar que o grupo apresentou os menores valores de ULS15 e ULS29 (fator 2), e diferiu estatisticamente dos demais grupos (Tabela 4). Essa característica decorreu, possivelmente, do estabelecimento mais tardio das relações parasitárias, o que pode ser confirmado pela análise dos valores de TxTr, na avaliação feita aos 7 DAI (Figura 2). Nessa avaliação, se constatou que o grupo $\mathrm{D}$ apresentou o valor de 1,70, enquanto no grupo A foi de 5,84, e no grupo $\mathrm{C}$ foi de 5,53 . Tal fato demonstra a presença da ação de componentes de resistência logo no início da interação. Entretanto, entre os 4 grupos formados, os genótipos do grupo D permitiram que o patógeno produzisse grande quantidade de urediniósporos (PRE15 e PRE29), mesmo com o mais baixo número de urédias por lesão (ULS15 e ULS29) (Tabela 4). Essa

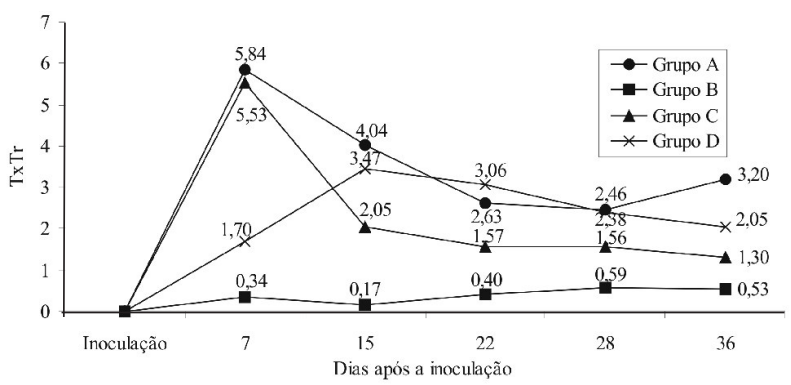

Figura 2. Taxa de infecção aparente (TxTr) dos grupos A, B, $\mathrm{C}$ e D, nas cinco avaliações realizadas após a inoculação . reação foi, possivelmente, um prenúncio da diminuição da resistência expressa inicialmente.

A partir da Figura 2, pode-se afirmar que a resistência inicial diminuiu no decorrer do desenvolvimento dos genótipos do grupo D. Após a primeira avaliação, esse grupo sofreu um pico na $\mathrm{TxTr}$, que resultou na correlação positiva com o fator 3 e manteve valores superiores ao grupo C, a partir da segunda (15 DAI) até a última avaliação (36 DAI).

A alta resistência inicial, seguida de queda nos genótipos do grupo $\mathrm{D}$, e a manifestação tardia da resistência no grupo $\mathrm{C}$ podem estar relacionadas à prevalência do padrão molecular de resistência de cada grupo. Durante a evolução da relação patógenohospedeiro, as plantas desenvolveram um sistema molecular de vigilância capaz de reconhecer diferentes tipos de moléculas codificadas por patógenos. Esse mecanismo de defesa é desencadeado pelos PMAP (padrões moleculares associados ao patógeno) e, aparentemente, é um sistema de defesa inicial (Nürnberger et al., 2004) e altamente conservado, mesmo com patógenos não relacionados.

Contudo, muitos patógenos conseguem superar essa barreira inicial. Assim, as plantas desenvolveram um segundo mecanismo de defesa, conferido pelos R-genes. Os R-genes codificam proteínas que reconhecem fatores específicos de virulência do patógeno (teoria gene a gene de Flor (1971)) e desencadeiam uma cascata de vias metabólicas, que resultam na resistência (McDowell \& Simon, 2006). É possível que a defesa induzida pelos PMAP atue com mais eficiência nos genótipos do grupo $\mathrm{D}$, enquanto nos genótipos do grupo C o sistema prevalente seja o de R-genes.

Os genótipos do grupo $\mathrm{D}$, juntamente com os do grupo $\mathrm{B}$, foram os que apresentaram as menores quantidades de doença (correlação negativa com o fator 1), apesar da alta TxTr e do alto EUR15 (fator 3). Essa menor expressão de doença total (AATr), em comparação aos grupos A e C, ocorreu, possivelmente, em razão da capacidade desses genótipos de atrasar o estabelecimento das relações parasitárias. Esse fato pode ser verificado no número de dias necessários, para os genótipos dos grupos B e D (11,91 e 8,34, respectivamente) atingirem $50 \%$ da severidade, contra 7,84 e 7,60 dos genótipos dos grupos A e C (Tabela 4). De forma análoga, Martins et al. (2007), ao medir o período latente médio, verificaram que ocorreu variação de 11,43 a 16,45 dias no patossistema 
soja-P. pachyrhizi. Esses autores afirmaram que cultivares com períodos latentes superiores a 14 dias poderiam ser classificados como portadores de resistência parcial. Contudo, o aumento de apenas um dia, para o estabelecimento das relações parasitárias, já é de significativa contribuição para a diminuição da quantidade de ciclos reprodutivos que um fungo pode realizar em uma safra (Vallavielle-Pope et al., 2000).

No entanto, os valores de AATr não diferiram estatisticamente entre os grupos C e D. Esse resultado pode ser evidência de que a presença da ação dos componentes de resistência, logo no início da interação, e de que uma possível resistência tardia, ativada no decorrer do desenvolvimento da planta (grupo C), são características interessantes e devem ser intensamente estudadas. Ainda, a combinação das duas características deve ser uma estratégia eficiente nos programas de melhoramento.

As comparações entre as médias dos grupos formados, em relação a uma mesma variável estudada, apresentaram diferenças significativas (Tabela 4). Com exceção da variável EUR15, todas as outras apresentaram coeficientes de variação $(\mathrm{CV})$ entre 1,14 e $15,73 \%$, o que denota alta precisão experimental (Pimentel-Gomes, 1985). Na variável EUR15, o CV de $76,74 \%$ foi muito alto. Essa discrepância deveuse, possivelmente, à grande variação nas quantidades de urediniósporos por urédia, na avaliação realizada 15 DAI. Nessa avaliação, alguns genótipos não apresentaram esporulação, enquanto outros esporularam abundantemente. Resultados obtidos por Santos et al. (2007), que avaliaram número de pústulas por $\mathrm{cm}^{2}$ e severidade em percentagem de área foliar infectada por P. pachyrhizi, em genótipos de soja, também apresentaram coeficientes de variação altos, de 41,21 e 50,40\%, em avaliações feitas aos 18 DAI e 6 DAI, respectivamente, fato que demonstrou as diferenças na reação dos genótipos estudados à ferrugem.

Com exceção dos padrões de suscetibilidade, situados no grupo $\mathrm{A}$, todos os demais 45 genótipos avaliados apresentaram lesões do tipo RB, o que foi associado à presença de genes únicos de resistência (Garcia et al., 2008). Foram observadas diferentes tipos de severidade dentro dos genótipos que apresentaram lesões RB, o que corrobora Miles et al. (2006). No presente trabalho, também foram observados diferentes níveis de NLS, NUD, PRE, ULS e EUR. Essas diferentes reações dos genótipos, em resposta à mesma população de $P$. pachyrhizi, pode ser explicada pela presença de genes de resistência parcial ou de tolerância, combinados a genes qualitativos de resistência.

A relação do número de urédias por lesão (ULS) não foi importante para selecionar genótipos quanto à sua resistência quantitativa (Melching et al., 1979; Berger et al., 1997; Bergamin Filho, 2006), pela metodologia adotada no presente trabalho. Os genótipos do grupo A (que desenvolveram a maior quantidade de doença) e a sua antonímia, os do grupo B (que desenvolveram a menor quantidade de doença), apresentaram alto ULS15 e ULS29. Contudo, as razões para tanto foram distintas, conforme discutido anteriormente. Ainda, essas variáveis não diferiram estatisticamente entre si, e nem do grupo $C$, nas avaliações aos 15 e 29 DAI (Tabela 4).

Entre todas as variáveis analisadas, as que apresentaram importância prática para diferenciar os genótipos foram as respostas qualitativas (tipo de lesão e nota de intensidade de esporulação) e as avaliações de severidade da doença. Essa última variável reflete os efeitos combinados de resistência sobre todos os componentes envolvidos (Broers, 1997), inclusive a taxa de infecção aparente que, no presente trabalho, foi calculada a partir dos dados de severidade.

Os grupos $\mathrm{B}, \mathrm{C}$ e $\mathrm{D}$ demonstraram características diferentes e interessantes quanto às respostas de resistência a $P$. pachyrhizi. Todos apresentaram lesões $\mathrm{RB}$, sendo os genótipos que não manifestaram lesões tipo MX os mais promissores para utilização em programas de melhoramento genético. Em relação às demais características, as respostas entre os grupos variaram quanto à resistência inicial, resistência tardia, intensidade de esporulação, produtividade de urediniósporos, e número de dias até que a doença atingisse $50 \%$ da severidade máxima (Tabela 4). De acordo com esse conjunto de características, os três grupos apresentaram menor quantidade de doença, quando comparados ao grupo $\mathrm{A}$.

Os resultados deste trabalho indicam que estudos genéticos devem ser conduzidos para se determinar a possibilidade de combinar as características quantitativas distintas de cada grupo, isto é, baixa quantidade de 
doença (grupo B), resistência tardia (grupo C), e alta resistência inicial (grupo D), em um mesmo genótipo.

\section{Conclusões}

1. As características lesões RB, resistência inicial, resistência tardia, intensidade de esporulação, produtividade de urediniósporos e número de dias até atingir $50 \%$ da severidade máxima conferem aos genótipos dos grupos B, C e D elevado potencial para uso como fontes de resistência a Phakopsora pachyrhizi.

2. Os parâmetros tipo de lesão, intensidade de esporulação e avaliação periódica da severidade apresentam importância prática para a diferenciação de genótipos quanto à resistência a Phakopsora pachyrhizi.

\section{Agradecimentos}

Ao Conselho Nacional de Desenvolvimento Científico e Tecnológico, por concessão de bolsa; aos técnicos e funcionários da Tropical Melhoramento \& Genética Ltda., pelo auxílio na condução dos ensaios; à professora Inês Cristina Batista Fonseca, da Universidade Estadual de Londrina, e aos pesquisadores Rafael Fuentes Llanillo e Moacir Doretto, do Instituto Agronômico do Paraná, pelo ensino do uso das ferramentas para executar e interpretar os dados gerados pelas análises multivariadas.

\section{Referências}

BERGAMIN FILHO, A. Epidemiologia comparativa: ferrugem da soja e outras doenças. In: LAÉRCIO ZAMBOLIM. (Org.). Ferrugem-asiática-da-soja. Viçosa: UFV, 2006. v.1. p.15-35.

BERGAMIN FILHO, A.; AMORIM, L. Doenças de plantas tropicais: epidemiologia e controle econômico. São Paulo: Agronômica Ceres, 1996. 289p.

BERGAMIN FILHO, A.; KIMATI, H.; AMORIM, L. Manual de fitopatologia: princípios e conceitos. 3.ed. São Paulo: Agronômica Ceres, 1995. 919p.

BERGER, R.D.; BERGAMIN FILHO, A.; AMORIM, L. Lesion expansion as an epidemic component. Phytopathology, v.87, p.1005-1013, 1997.

BROERS, L.H.M. Components of quantitative resistance to yellow rust in ten spring bread wheat cultivars and their relations with field assessments. Euphytica, v.96, p.215-223, 1997.

BROMFIELD, K.R. Soybean rust. Saint Paul: American Phytopathological Society, 1984.65p. (American Phytopathological Society. Monograph, 11).
BROMFIELD, K.R.; HARTWIG, E.E. Resistance to soybean rust and mode of inheritance. Crop Science, v.20, p.254-255, 1980.

BURDON, J.J.; SPEER, S.S. A set of differential Glycine hosts for the identification of races of Phakopsora pachyrhizi Syd. Euphytica, v.33, p.891-896, 1984.

CAMPBELL, C.L.; MADDEN, L. Introduction to plant disease epidemiology. New York: Wiley, 1990. 532p.

CANTERI, M.G.; ALTHAUS, R.A.; VIRGENS FILHO, J.S. das; GIGLIOTI, E.A.; GODOY, C.V. SASM-Agri: sistema para análise e separação de médias em experimentos agrícolas pelos métodos Scott-Knott, Tukey e Duncan. Revista Brasileira de Agrocomputação, v.1, p.18-24, 2001.

FEHR, W.R.; CAVINESS, C.E. Stages of soybean development. Ames: Iowa State University, 1977. 12p.

FLOR, H.H. Current status of the gene-for-gene concept. Annual Reviews of Phytopathology, v.9, p.275-296, 1971.

GARCIA, A.; CALVO, E.S.; KIIHL, R.A. de S.; HARADA, A.; HIROMOTO, D.M.; VIEIRA, L.G.E. Molecular mapping of soybean rust (Phakopsora pachyrhizi) resistance genes: discovery of a novel locus and alleles. Theoretical and Applied Genetics, v.117, p.545-553, 2008.

GODOY, C.V.; KOGA, L.J.; CANTERI, M.G. Diagrammatic scale for assessment of soybean rust severity. Fitopatologia Brasileira, v.31, p.63-68, 2006.

HAIR JUNIOR, J.F.; ANDERSON, R.E.; TATHAM, R.L.; BLACK, W.C. Análise multivariada de dados. 5.ed. Porto Alegre: Bookman, 2005. 600p.

HARMAN, H.H. Modern factor analysis. Chicago: University of Chicago Press, 1976. 487p.

HARTMAN, G.L.; MILES, M.R.; FREDERICK, R.D. Breeding for resistance to soybean rust. Plant Disease, v.89, p.664-665, 2005.

HARTMAN, G.L.; WANG, T.C.; SHANMUGASUNDARAM, S. Soybean rust research: progress and future prospects. In: WORLD SOYBEAN RESEARCH CONFERENCE, 5., 1994, Chiang Mai. Proceedings. Bangkok: Kasetsart University Press, 1997. p.180-186.

HARTMAN, G.L.; WANG, T.C.; TSCHANZ, A.T. Soybean rust development and quantitative relationship between rust severity and soybean yield. Plant Disease, v.75, p.596-600, 1991.

HARTWIG, E.E. Identification of a fourth major gene conferring resistance to soybean rust. Crop Science, v.26, p.1135-136, 1986.

HARTWIG, E.E.; BROMFIELD, K.R. Relationships among three genes conferring specific resistance to rust in soybeans. Crop Science, v.23, p.237-239, 1983.

HEAGLE, A.S.; MOORE, M.B. Some effects of moderate adult resistance to crown rust of oats. Phytopathology, v.60, p.461-466, 1970.

KAWUKI, R.S.; ADIPALA, E.; TUKAMUHABWA, P. Yield loss associated with soya bean rust (Phakopsora pachyrhizi Syd.) in Uganda. Journal of Phytopathology, v.151, p.7-12, 2003. 
MARTINS, J.A.S.; JULIATTI, F.C.; SANTOS, V.A.; POLIZEL, A.C.; JULIATTI, F.C. Período latente e uso da análise de componentes principais para caracterizar a resistência parcial à ferrugem-da-soja. Summa Phytopathologica, v.33, p.364-371, 2007.

MCDOWELL, J.M.; SIMON, S.A. Recent insights into R gene evolution. Molecular Plant Pathology, v.7, p.437-448, 2006.

MCLEAN, R.J.; BYTH, D.E. Inheritance of resistance to rust (Phakopsora pachyrhizi) in soybeans. Australian Journal of Agriculture Research, v.31, p.951-956, 1980.

MELCHING, J.S.; BROMFIELD, K.R.; KINGSOLVER, C.H. Infection, colonization, and uredospore production on Wayne soybean by four cultures of Phakopsora pachyrhizi, the cause of soybean rust. Phytopathology, v.69, p.1262-1265, 1979.

MILES, M.R.; FREDERICK, R.D.; HARTMAN, G.L. Evaluation of the soybean germplasm for resistance to Phakopsora pachyrhizi. Plant Health Progress. 2006. doi 10.1094/PHP-0104-01-RS. Disponível em: <http://www.plantmanagementnetwork.org/pub/ php/research/2006/germplasm/>. Acesso em: 30 set. 2008.

NÜRNBERGER， T.; BRUNNER， F.; KEMMERLING， B.; PIATER, L. Innate immunity in plants and animals: striking similarities and obvious differences. Immunological Reviews, v.198, p.249-266, 2004

PARLEVLIET, J.E. Components of resistance that reduce the rate of epidemic development. Annual Review of Phytopathology, v.17, p.203-222, 1979.

PIMENTEL-GOMES, F. Curso de estatística experimental. São Paulo: Nobel, 1985. 487p.
SANTOS, J.A.; JULIATTI, F.C.; SANTOS, V.A.; POLIZEL, A.C.; JULIATTI, F.C.; HAMAWAKI, O.T. Caracteres epidemiológicos e uso da análise de agrupamento para resistência parcial à ferrugemda-soja. Pesquisa Agropecuária Brasileira, v.42, p.443-447, 2007.

TSCHANZ, A.T.; WANG, T.C. Interrelationship between soybean development, resistance, and Phakopsora pachyrhizi. In: INTERNATIONAL CONGRESS OF THE SOCIETY FOR THE ADVANCED OF BREEDING RESEARCH IN ASIA AND OCEANIA, 5., 1985. Bangkok. Proceedings. Bangkok: Society for the Advanced of Breeding Research in Asia and Oceania, 1985. p.14-20.

VALLAVIEILLE-POPE,C.de;GIOSUE,S.;MUNK,L.;NEWTON, A.C.; NIKS, R.E.; OSTERGARD, H.; PONS-KUHNEMANN, J.; ROSSI, V.; SACHE, I. Assessment of epidemiological parameters and their use in epidemiological and forecasting models of cereal airborne diseases. Agronomie, v.20, p.715-727, 2000.

YAMAOKA, Y.; FUJIWARA, Y.; KAKISHIMA, M.; KATSUYA, K.; YAMADA, K.; HAGIWARA, H. Pathogenic races of Phakopsora pachyrhizi on soybean and wild host plants collected in Japan. Journal of General Plant and Pathology, v.68, p.52-56, 2002.

YORINORI, J.T. Ferrugem "asiática" da soja: o desafio continua e como aprimorar o seu controle. In: CONGRESSO BRASILEIRO DE SOJA, 4., 2006, Londrina. Anais. Londrina: Embrapa Soja, 2006. p.102-108.

YORINORI, J.T.; LAZZAROTTO, J.J. Situação da ferrugemasiática-da-soja no Brasil e na América do Sul. Londrina: Embrapa Soja, 2004. 27p. (Embrapa Soja. Documentos, 236).

Recebido em 24 de julho de 2008 e aprovado em 22 de setembro de 2008 